\title{
Tauroursodeoxycholic acid inhibits experimental colitis by preventing early intestinal epithelial cell death
}

\author{
Debby Laukens ${ }^{1,5}$, Lindsey Devisscher ${ }^{1,5}$, Lien Van den Bossche ${ }^{1}$, Pieter Hindryckx ${ }^{1}$, \\ Roosmarijn E Vandenbroucke ${ }^{2,3}$, Yves-Paul Vandewynckel ${ }^{1}$, Claude Cuvelier ${ }^{4}$, Brigitta M Brinkman ${ }^{3}$, \\ Claude Libert ${ }^{2,3}$, Peter Vandenabeele ${ }^{2,3}$ and Martine De Vos ${ }^{1}$
}

Ulcerative colitis (UC) is characterized by increased epithelial cell death and subsequent breakdown of the intestinal epithelial barrier, which perpetuates chronic intestinal inflammation. Since fecal bile acid dysmetabolism is associated with UC and tauroursodeoxycholic acid (TUDCA) has been shown to improve murine colitis, we evaluated the effect of TUDCA on intestinal epithelial cell death in a mouse model of UC-like barrier dysfunction elicited by dextran sulfate sodium (DSS). We identified the prevention of colonic caspase-3 induction, a key proapoptotic marker which was also over-activated in UC, as the earliest event resulting in a clear clinical benefit. Whereas vehicle-treated mice showed a cumulative mortality of $40 \%$, all TUDCA-treated mice survived the DSS experiment during a 14-day follow-up period. In line with a barrier protective effect, TUDCA decreased bacterial translocation to the spleen and stimulated mucin production. Similarly, TUDCA inhibited lipopolysaccharide-induced intestinal permeability and associated enterocyte apoptosis. The anti-apoptotic effect was confirmed in vitro by a dose-dependent inhibition of both receptor-dependent (using tumor necrosis factor and Fas ligand) and receptor-independent (staurosporine) caspase-3 induction in HT29 colonic epithelial cells. These data imply that caspase-3 activation is an early marker of colitis that is prevented by TUDCA treatment. These data, together with the previously reported beneficial effect in colitis, suggest that TUDCA could be an add-on strategy to current immunosuppressive treatment of UC patients.

Laboratory Investigation (2014) 94, 1419-1430; doi:10.1038/labinvest.2014.117; published online 13 October 2014

Immune homeostasis in the gastrointestinal tract requires an intact epithelial barrier that acts as an interface between the 'outside' lumen and the underlying immune compartment. This epithelial cell layer is continuously renewed by controlled cell proliferation and cell death. Any imbalance in this process causes barrier disruption, which is a major contributing factor in ulcerative colitis (UC), a chronic and relapsing inflammatory bowel disease (IBD). ${ }^{1}$ During normal gut homeostasis, only superficial epithelial cells undergo apoptosis, and carefully coordinated mechanisms close the gaps that are formed without impairing barrier function. ${ }^{2,3}$ Uncontrolled excessive apoptosis of colonocytes permits the influx of antigens from the intestinal lumen, which trigger antigen-presenting cells residing in the lamina propria. Such dysregulated apoptosis throughout the complete crypt-villus axis has been observed in active lesions of patients with UC. ${ }^{4}$ In addition, inflamed colonic tissue from untreated UC patients contains increased numbers of TUNEL-positive epithelial cells, particularly in lower to midcrypt regions containing the indispensible stem cells. ${ }^{5}$ High levels of proinflammatory cytokines, such as tumor necrosis factor alpha (TNF) and interferon gamma (IFNG), play a pivotal role in this process by mediating the downregulation of antiapoptotic signals, including the expression of B-cell CLL/ lymphoma $2(\mathrm{Bcl} 2){ }^{6}$

Several animal models point to a causal role for epithelial apoptosis in intestinal inflammation. In the acute model for colitis elicited by dextran sulfate sodium (DSS), increased numbers of apoptotic bodies and TUNEL-positive colonocytes have been identified, and genetic ablation of apoptotic regulators protects mice from DSS-induced colitis., $5,7,8$ Therefore, inhibition of intestinal epithelial apoptosis appears to be a promising therapeutic strategy to prevent barrier disruption.

\footnotetext{
${ }^{1}$ Department of Gastroenterology, Ghent University, Gent, Belgium; ${ }^{2}$ Department for Molecular Biomedical Research, Ghent University, Gent, Belgium; ${ }^{3}$ nflammation Research Center (IRC), VIB, Zwijnaarde, Belgium and ${ }^{4}$ Department of Pathology, Ghent University, Gent, Belgium

Correspondence: Dr D Laukens, PhD, Department of Gastroenterology, Ghent University Hospital, De Pintelaan 185, 1K12IE, Gent B-9000, Belgium.

E-mail: debby.laukens@ugent.be

${ }^{5}$ These authors contributed equally to this work.

Received 28 February 2014; revised 4 August 2014; accepted 25 August 2014
} 
Bile salts are important regulators of epithelial cell viability in the gastrointestinal lumen. ${ }^{9}$ Recently, decreased concentrations of secondary bile salts have been found in fecal samples of patients with IBD. ${ }^{10}$ Whereas the severity of colitis in mice is correlated with hydrophobicity of fecal bile acids, ${ }^{9}$ the more hydrophilic bile acids exhibit anti-inflammatory effects on epithelial cells in vitro. ${ }^{11-13}$ A secondary and hydrophilic bile salt that has long been studied for its potent cytoprotective properties is tauroursodeoxycholic acid (TUDCA), which is the taurine-coupled conjugate of ursodeoxycholic acid, a drug that is routinely used for the treatment of primary biliary cirrhosis and to some extent of primary sclerosing cholangitis. Since TUDCA inhibits apoptosis of hepatocytes ${ }^{14}$ and recently has been shown to reduce experimental colitis by abolishing endoplasmic reticulum stress in colonocytes, ${ }^{15}$ we aimed to investigate the effect of TUDCA on intestinal epithelial cell death and barrier dysfunction in a mouse model for UC.

\section{MATERIALS AND METHODS Ethics Statement}

Animals were housed in the laboratory animal facility at Ghent University Hospital according to the institutional animal healthcare guidelines. This study was approved by the Institutional Review Board of the Faculty of Medicine and Health Science of Ghent University (ECD2011-054 and ECD2013-061). The use of patient material was approved by the Ethics Committee of Ghent University Hospital (permit no. UZG2004/242), and each participant dated, signed, and received a written informed consent form.

\section{DSS Induction and TUDCA Treatment}

Fifty-eight 8- to 10-week-old male C57BL/6 mice were purchased from Harlan (Harlan Laboratories, Horst, The Netherlands) and housed in a temperature-controlled room at $20^{\circ} \mathrm{C}$ with a $12: 12$-h light-dark cycle. The animals had free access to water and to a commercial chow (mice maintenance chow, Carfil Labofood, Pavan Service, Belgium). After 2 weeks of acclimatization, mice received 4\% DSS (molecular weight 36000-50000; MP Biomedicals, France) in their drinking water for 7 days, followed by normal drinking water for another 7 days. Prior to the experiment, mice were matched for initial body weight. Fifty percent of the mice were intraperitoneally (i.p.) injected with $500 \mathrm{mg} / \mathrm{kg} / \mathrm{day}$ TUDCA (Calbiochem, Germany), and the other 50\% received an equivalent volume of vehicle (PBS). ${ }^{16}$ Mortality and body weight were monitored daily. At days $0,3,7,10$, and $14, \geq 6$ animals from each group were killed by cervical dislocation. The colon was removed and colon length was measured. The colon was opened longitudinally and feces were removed by flushing with PBS. Fragments of $5 \mathrm{~mm}$ were cut and samples from distal to proximal were immersed in formol, Cell Recovery Solution (BD Biosciences, Bedford, MA, USA), ${ }^{17}$ or snap frozen. The spleen was removed, $50 \mathrm{mg}$ of tissue was homogenized in PBS and plated onto LB agar plates for colony counting after overnight growth.

\section{LPS Challenge and Determination of Intestinal Permeability}

Twenty-four female 8-week-old C57BL/6 mice were i.p. injected with $7 \mathrm{mg} / \mathrm{kg}$ LPS from Salmonella enterica serotype abortus equi (Sigma-Aldrich, Diegem, Belgium) or with PBS. LPS-challenged mice were divided in two groups, receiving either $500 \mathrm{mg} / \mathrm{kg}$ TUDCA or PBS (i.p.) $24 \mathrm{~h}$ and $15 \mathrm{~min}$ before LPS administration. One hour after the LPS challenge, FITC-labeled dextran (4 kDa; Sigma-Aldrich) was administered to mice by gavage at $125 \mathrm{mg} / \mathrm{kg}$. Five hours later, blood obtained by heart puncture was collected in EDTA-coated tubes (Sarstedt, Essen, Belgium) and plasma was prepared. Ileal tissue was collected in formol. Leakage of FITC-labeled dextran into the circulation was determined by measurement of the plasma fluorescence $(\lambda \mathrm{ex} / \lambda \mathrm{em}=488 / 520 \mathrm{~nm})$. Values were normalized to the lowest value.

\section{TUNEL Staining}

Apoptotic cells were detected in paraffin-embedded ileal tissue by TUNEL according to the manufactures' protocol (Promega, Wisconsin, USA), and nuclei were counterstained by DAPI (Life Technologies, Gent, Belgium). The mean number of TUNEL-positive epithelial nuclei were counted from six fields per mouse $(\times 400)$.

\section{Myeloperoxidase Assay}

Distal colon myeloperoxidase activity was determined as described previously. ${ }^{18}$

\section{Histological Assessment and Periodic Acid-Schiff Staining}

Colon sections were stained with hematoxylin and eosin and blindly scored for inflammation by two observers using a validated scoring system. ${ }^{19}$ The total histological inflammation score represents the sum of the scores for colon ulceration, influx of inflammatory cells in mucosa and submucosa, decrease of goblet cells, mucosal thickening, and destruction of mucosal architecture. Periodic acid-Schiff staining was performed according to the manufacturer's instructions (Sigma-Aldrich) and computerized semi-quantitative analysis of the stained regions was performed using the Cell D software (Olympus).

\section{Patient Samples}

For gene expression analysis, a total of 53 biopsies from 19 healthy controls and 22 UC patients were obtained from the sigmoid during colonoscopy with Single-Use Biopsy Forceps Radial Jaw3 (Boston Scientific, El Coyol, Costa Rica). UC was diagnosed based on clinical, endoscopic, and histological criteria (for patient characteristics see Table 1). Remission was defined as clinical remission and extinguished endoscopic inflammation. In 13 patients with endoscopic 
Table 1 Patient characteristics

\begin{tabular}{|c|c|c|c|c|}
\hline & $\begin{array}{l}\text { Healthy } \\
\text { controls }\end{array}$ & $\begin{array}{c}\text { UC } \\
\text { uninvolved }\end{array}$ & $\begin{array}{c}\text { UC } \\
\text { involved }\end{array}$ & $\begin{array}{c}\text { UC } \\
\text { remission }\end{array}$ \\
\hline \multicolumn{5}{|l|}{ For gene expression } \\
\hline$N$ (biopsies) & 19 & 13 & 16 & 5 \\
\hline Gender (male/female) & $4 / 15$ & $5 / 8$ & $7 / 9$ & $4 / 1$ \\
\hline Age (years, mean) & 48 & 41 & 39 & 51 \\
\hline Age (years, range) & $12-73$ & $14-58$ & $14-58$ & $27-71$ \\
\hline Age at diagnosis (years, mean) & N/A & 37 & 35 & 38 \\
\hline Age at diagnosis (years, range) & N/A & $13-58$ & $13-58$ & $22-64$ \\
\hline Disease location (E1/E2/E3) & N/A & $3 / 8 / 2$ & $3 / 10 / 3$ & $0 / 4 / 1$ \\
\hline \multicolumn{5}{|l|}{ Medication } \\
\hline No & 19 & 4 & 8 & 3 \\
\hline 5-Aminosalicylates & 0 & 9 & 8 & 2 \\
\hline \multicolumn{5}{|l|}{ For caspase-3 activity } \\
\hline$N$ (biopsies) & 6 & 6 & 10 & 7 \\
\hline Gender (male/female) & $3 / 3$ & $5 / 1$ & $8 / 2$ & $5 / 2$ \\
\hline Age (years, mean) & 49 & 51 & 43 & 43 \\
\hline Age (years, range) & $29-62$ & $38-68$ & $11-68$ & $23-72$ \\
\hline Age at diagnosis (years, mean) & N/A & 40 & 31 & 32 \\
\hline Age at diagnosis (years, range) & $\mathrm{N} / \mathrm{A}$ & $35-44$ & $11-44$ & $17-62$ \\
\hline Disease location (E1/E2/E3) & $\mathrm{N} / \mathrm{A}$ & $1 / 4 / 1$ & $1 / 5 / 4$ & $0 / 2 / 5$ \\
\hline \multicolumn{5}{|l|}{ Medication } \\
\hline No & 19 & 0 & 1 & 0 \\
\hline 5-Aminosalicylates & 0 & 2 & 3 & 1 \\
\hline Corticosteroids & 0 & 3 & 4 & 0 \\
\hline Immunomodulators & 0 & 1 & 2 & 4 \\
\hline Biologicals & 0 & 0 & 0 & 2 \\
\hline
\end{tabular}

E1: proctitis; E2: distal colitis; E3: pancolitis.

signs of disease activity, both inflamed and non-inflamed samples were retrieved. Samples from healthy controls were taken from the sigmoid of patients who underwent colonoscopy to screen for cancer. All biopsies collected during colonoscopy were immediately placed in RNAlater (Ambion, Cambridgeshire, UK) and stored at $-80^{\circ} \mathrm{C}$. To determine caspase- 3 activity, a total of 29 biopsies were retrieved from 6 healthy controls and 23 UC patients (for patient characteristics see Table 1), and biopsies were lysed in RIPA buffer supplemented with protease inhibitors (Roche, Belgium).

\section{ELISA}

The concentration of IL1B was measured by ELISA in tissue homogenates (R\&D Systems) according to the manufacturer's instructions. Total protein concentration was measured using the Bradford method (Bio-Rad, Nazareth Eke, Belgium).

\section{RNA Extraction}

Total RNA was extracted using the Qiagen RNeasy mini kit (Qiagen Benelux, Venlo, The Netherlands) with on-column DNase treatment. The concentration and purity of the total RNA was determined using a spectrophotometer (WPA Biowave II, Isogen Life Science, Belgium). All samples exhibited an OD260/OD280 ratio between 1.8 and 2.1.

\section{Quantitative Real-Time PCR}

One microgram of total RNA was converted to singlestranded cDNA by reverse transcription using the SuperScript enzyme (Life Technologies) with oligo(dT) priming. The cDNA was diluted $1 / 10$ and used in real-time PCR with SYBR Green (Sensimix, Bioline Reagents, UK) and $250 \mathrm{mM}$ of each primer. A two-step program was performed on the LightCycler 480 . Cycling conditions were $95^{\circ} \mathrm{C}$ for $10 \mathrm{~min}$, 45 cycles of $95^{\circ} \mathrm{C}$ for $10 \mathrm{~s}$, and $60^{\circ} \mathrm{C}$ for $1 \mathrm{~min}$. Melting curve analysis confirmed primer specificities. All reactions were performed in duplicate and were normalized to glyceraldehyde-3-phosphate dehydrogenase (GAPDH) and succinate dehydrogenase complex subunit A (SDHA) expression for mouse cDNA and SDHA alone for human cDNA, and was based on the stability of the reference genes between the different groups. The PCR efficiency of each primer pair was calculated using a standard curve of reference cDNA. Amplification efficiency was determined using the formula $10^{-1 / \text { slope }}$. The sequences of the primer sets are listed in Table 2.

\section{Caspase-3 Activity Assay in Colonic Tissue}

Freshly isolated colonocytes, prepared using Cell Recovery Solution, were lysed in RIPA buffer supplemented with phosphatase and protease inhibitors. Caspase- 3 activity was assayed in lysates containing $10 \mu \mathrm{g}$ protein. The assay was performed in cell-free system buffer (10 mM HEPES pH 7.5, $220 \mathrm{mM}$ mannitol, $68 \mathrm{mM}$ sucrose, $2 \mathrm{mM} \mathrm{NaCl}, 2 \mathrm{mM}$ $\mathrm{MgCl} 2$, and $2.5 \mathrm{mM} \mathrm{KH}_{2} \mathrm{PO}_{4}$ ) supplemented with $10 \mathrm{mM}$ dithiothreitol and $50 \mu \mathrm{M}$ Ac-DEVD-AMC (PeptaNova, Sandhausen, Germany). The release of fluorescent aminomethylcoumarin was measured immediately for $1 \mathrm{~h}$ at 2 -min intervals (excitation at $360 \mathrm{~nm}$ and emission at $480 \mathrm{~nm}$; FLUOstar Omega, BMG Labtech, Germany); the increase in fluorescence per minute was calculated.

\section{Cell Culture and Induction of Apoptosis In Vitro}

HT29 cells (HTB-38, ATCC Cell Biology Collection, Virginia, USA) were seeded in 96-well plates, with each well containing $5 \times 10^{5}$ cells in McCoy's medium supplemented with $10 \%$ fetal calf serum (FCS; Life Technologies). The next day, the cells were incubated with recombinant human $100 \mathrm{ng} / \mathrm{ml}$ TNF (Life Technologies) and $300 \mathrm{ng} / \mathrm{ml}$ IFNG (R\&D Systems, 
Table 2 Primers for qRT-PCR analysis

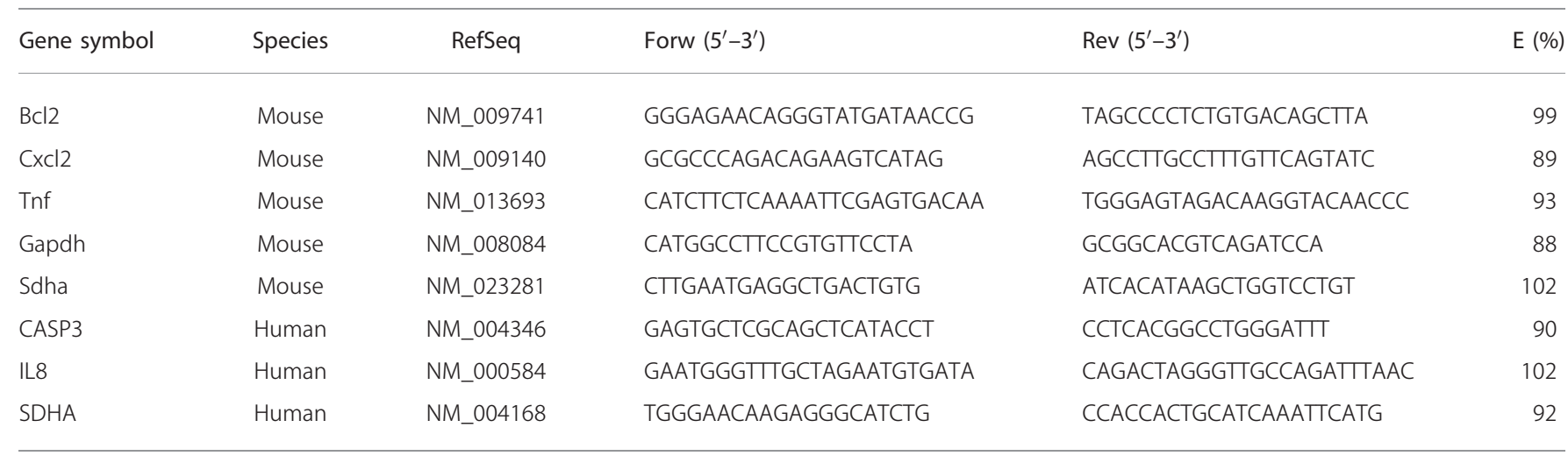

UK), $200 \mathrm{ng} / \mathrm{ml}$ FasL (Enzo Life Sciences, Antwerpen, Belgium) or $10 \mu \mathrm{M}$ staurosporine (Sigma-Aldrich) for 24,96 , and $6 \mathrm{~h}$, respectively, and a combination of 1-10 mM TUD$\mathrm{CA}$ or an equal volume of medium. Each condition was performed in triplicate. After $24 \mathrm{~h}$, caspase-3, -8 , and -9 activity was measured using the Caspase-Glo Assay system (Promega) and additionally, dead/live cells were counted using trypan blue on a hemocytometer after TNF/IFN induction. In the preincubation experiments, $10 \mathrm{mM}$ TUDCA was added to the cells during $6 \mathrm{~h}$. The cells were washed three times with PBS, and stimulated with TNF and IFNG, FasL, or staurosporine for 24, 96, and $6 \mathrm{~h}$, respectively. For kinase and integrin inhibition, HT29 cells were seeded in 96-well plates, with each well containing $5 \times 10^{5}$ cells in McCoy's medium supplemented with $10 \%$ FCS. The cells were preincubated for $1 \mathrm{~h}$ with $100 \mathrm{nM}$ wortmannin (SigmaAldrich) or $10 \mu \mathrm{M}$ GRGDSP peptide (Sigma-Aldrich) followed by a preincubation period with $10 \mathrm{mM}$ TUDCA for another $6 \mathrm{~h}$. Next, the cells were washed three times with PBS and stimulated with TNF and IFNG for $24 \mathrm{~h}$.

\section{Transmission Electron Microscopy}

Glutaraldehyde/paraformaldehyde fixed T84 cell cultures grown in transwells were rinsed overnight in $0.1 \mathrm{M}$ sodium cacodylate buffer ( $\mathrm{pH}$ 7.4). Slices were post-fixed in $1 \%$ buffered osmium tetroxide (Merck, NJ), dehydrated in a series of alcohol and embedded in Epon (Aurion, The Netherlands). Semi-thin $(1 \mu \mathrm{m})$ sections, stained with toluidine blue, facilitated orientation of the tissue. Ultra-thin $(90 \mathrm{~nm}) \mathrm{sec}-$ tions were cut, contrasted with uranyl acetate and lead citrate and examined in a Zeiss TEM 900 at $50 \mathrm{kV}$ (Carl Zeiss, Germany).

\section{Cytotoxicity Assay}

HT29 cells were seeded in 96-well plates, with each well containing $5 \times 10^{5}$ cells in McCoy's medium supplemented with $10 \%$ FCS and stimulated the next day with a dilution series of TUDCA ( $10 \mathrm{mM}$ to $1.25 \mathrm{mM}$, twofold dilutions) or
$1 \%$ Triton X-100 as positive control. After $24 \mathrm{~h}, 100 \mu \mathrm{l} \mathrm{su}-$ pernatant was collected for lactate dehydrogenase (LDH) measurement (Biovision, California, USA), and the cells were incubated for an additional $3 \mathrm{~h}$ with 3-(4,5-dimethylthiazol2-yl)-2,5-diphenyltetrazolium bromide (MTT, Sigma-Aldrich). Supernatant was discarded, and the MTT precipitate was dissolved in DMSO and measured at $570 \mathrm{~nm}$ (Multiskan Ascent, VWR International, Leuven, Belgium).

\section{Statistics}

Statistical analysis was performed using GraphPad Prism software (GraphPad, California, USA) and SPSS Statistics version 21 (Chicago, USA). Values are presented as the mean \pm s.e.m. Survival was analyzed using the Kaplan-Meier test (censored data). Weight evolution over time was compared between groups using a linear mixed model. The Student's unpaired $t$-test was used to compare differences between two groups, applying the Welch's correction in the case of unequal variances. Multiple groups were compared by one-way ANOVA with a Bonferroni correction for the number of comparisons made. Two-tailed probabilities were calculated and $P$ values of less than 0.05 were considered statistically significant.

\section{RESULTS \\ TUDCA Prevents DSS-Induced Mortality and Morbidity in Mice}

All mice that received TUDCA $(N=29)$ survived DSSinduced colitis after a 14-day follow-up period, whereas a cumulative mortality of $40 \%$ was observed in PBS-treated animals $(N=29$ at the start of the experiment, $P=0.017$; Figure 1a). In addition, TUDCA-treated mice showed significantly less body weight reduction during DSS treatment $(P<0.001$; Figure $1 \mathrm{~b})$, which was accompanied by less colon shortening at day $10(P=0.006$; Figure 1c) and slightly reduced myeloperoxidase levels $(1.90 \pm 0.22 \mu / \mathrm{mg}$ protein $v s$ $1.33 \pm 0.16 \mu / \mathrm{mg}$ protein, $P=0.06$ ), compared to the mice that survived in the control group. Because of significant 

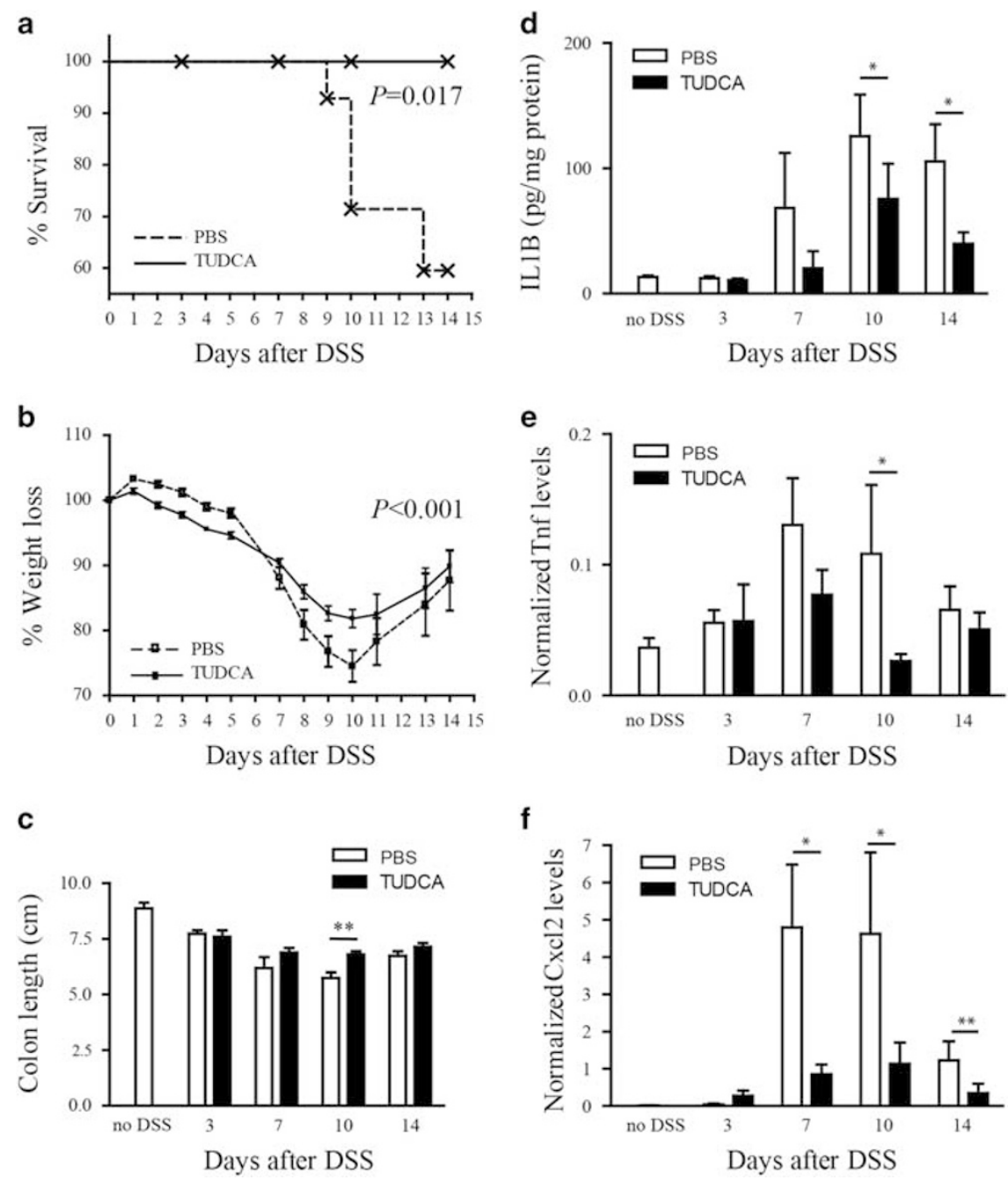

Figure 1 Disease activity parameters in TUDCA- and placebo-treated mice during DSS-induced colitis. (a) Mortality (censored data), (b) weight loss, (c) colon shortening, and (d-f) the expression of colonic proinflammatory cytokine IL1B protein levels, and Cxcl2 and Tnf mRNA expression during the course of DSS-induced colitis. $N \geq 6$ at each time point. ${ }^{*} P<0.05,{ }^{*} P<0.01$.

mortality, survivorship bias is introduced during tissue sampling, which may underestimate the therapeutic effect. Nonetheless, colonic expression of the proinflammatory cytokines IL1B protein, and Tnf and Cxcl2 (the murine homolog of human IL8) mRNA at days 7 and 10 post DSS were significantly reduced compared to placebo-treated survivors (Figures $1 \mathrm{~d}-\mathrm{f}$ ).

The overall histological score did not differ significantly, however, the presence of erosions and goblet cell loss tended to be reduced in the TUDCA-treated mice $(P=0.14$ and $P=0.22$, respectively, Figure 2a). Consistently, bacterial translocation to the spleen, indicating increased permeability of the gut, was significantly diminished in the TUDCA-treated mice (Figure 2b). In addition, PAS staining of mucins in the colon was increased in the TUDCAtreated mice $(P<0.05$ at days 3 and 10 ; Figures $2 \mathrm{c}$ and $\mathrm{d})$. During recovery (day 14) PAS staining was significantly increased in the placebo-treated DSS group $(P=0.05$; Figure 2c).

\section{Colonic Epithelial Apoptosis Precedes Inflammation in DSS-Induced Colitis and is Prevented by TUDCA}

The presence and onset of intestinal epithelial cell apoptosis was evaluated at various time points during the DSS experiment. At day 3, before any microscopic signs of epithelial damage were observed, freshly prepared colonocytes of DSS-treated animals showed increased caspase- 3 activity as compared to mice that did not receive DSS $(P=0.036$; Figure 3a), as well as decreased anti-apoptotic Bcl2 mRNA levels $(P=0.002$; Figure $3 \mathrm{~b})$. The induction of caspase-3 activity before clinical inflammation was significantly reduced in TUDCA-treated mice as compared to placebotreated mice $(P=0.005$; Figure $3 \mathrm{a})$, whereas Bcl2 levels remained at baseline (Figure $3 b$ ). 

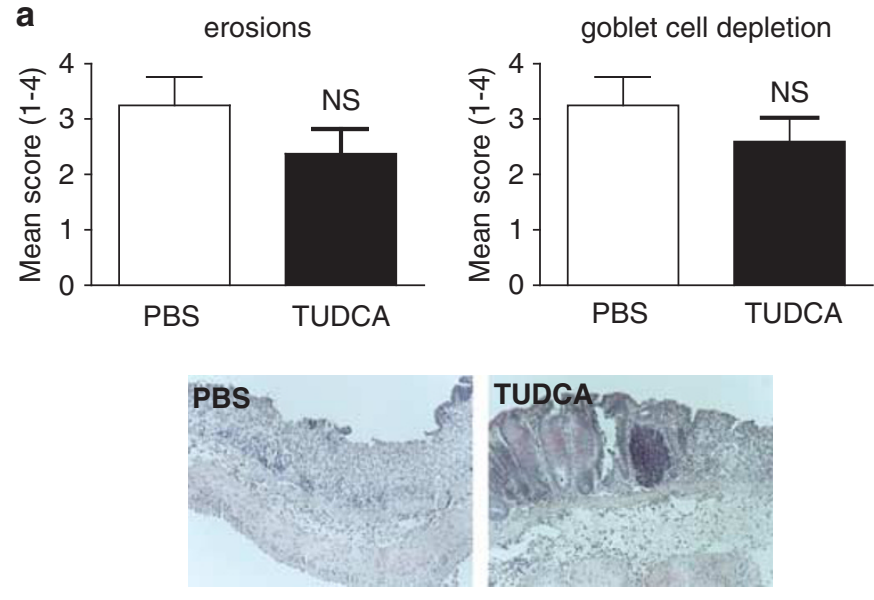

b

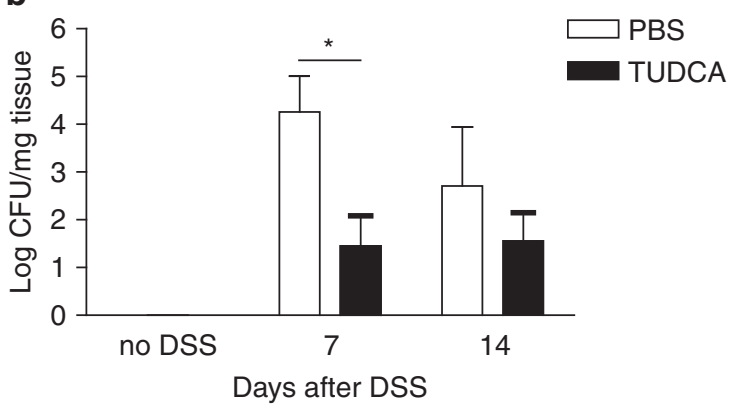

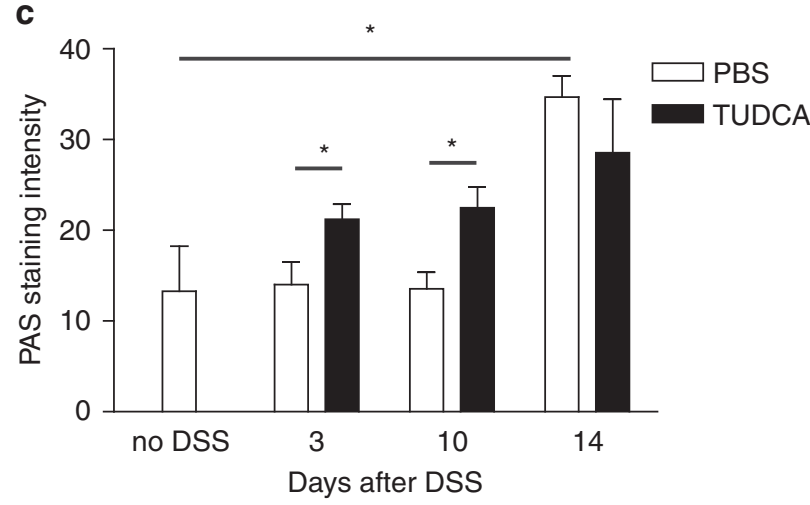

d

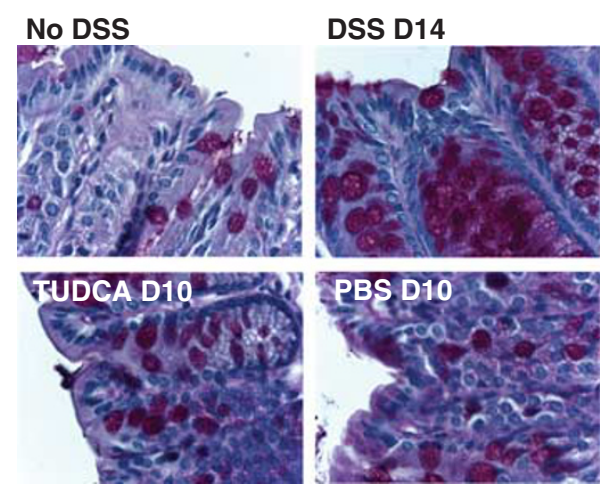

Figure 2 Histology and intestinal epithelial barrier function in TUDCA- and placebo-treated mice. (a) Histological scoring and representative images ( $\times 200$ ) of the colon of TUDCA- and placebo-treated mice at day 10 post DSS. (b) The number of bacteria found in the spleen at days 0 (no DSS), 7 and 14 post DSS and (c) quantitative analysis of periodic acid-Schiff staining in the colon of TUDCA- and placebo-treated animals during the course of DSS-induced colitis. (d) Representative images $(\times 1000)$ of periodic acid-Schiff-stained colon sections of TUDCA- and placebo-treated animals at days 0 (no DSS), 3,10 , and 14 post DSS. $N \geq 6$ at each time point. ${ }^{*} P<0.05$. NS, not significant; CFU, colony forming units.

\section{Caspase-3 Expression and Activity is Increased in both Uninvolved and Involved Areas of the Colon of UC Patients}

The clinical value of increased caspase- 3 activation was in whole pinch biopsies from UC patients. Caspase-3 mRNA levels and its activity were increased in biopsies that were retrieved from actively inflamed areas of the colon of UC patients compared to tissue from healthy controls $(P<0.001$ and $P<0.01$, respectively; Figures $4 \mathrm{a}$ and $\mathrm{b})$. Interestingly, significantly higher levels of caspase- 3 were also found in uninvolved areas of the gut in UC patients with active disease $(P=0.007$ for mRNA level and $P=0.001$ for activity, Figure $4 \mathrm{a}$ and b) but not in patients who were in remission at the time of sampling. Paired biopsies from involved and uninvolved areas within the same patient expressed similar caspase-3 levels (Figure 4c), as opposed to the expression of IL8, which was typically increased in involved compared to uninvolved areas $(P=0.018$; Figure $4 \mathrm{~d})$. Immunohistochemical analysis for the active (cleaved) form of caspase-3 showed staining in colonocytes (Figure 4e) and to a lesser extent in inflammatory cells.

\section{TUDCA Inhibits LPS-Induced Intestinal Permeability and Enterocyte Apoptosis}

The anti-apoptotic effect of TUDCA was tested in another model of enterocyte apoptosis induced by LPS. In this model, ileal TNF levels peak after $1 \mathrm{~h}$ and are responsible for increased permeability, inflammation, and mucus depletion in these mice. ${ }^{20}$ The administration of $500 \mathrm{mg} / \mathrm{kg}$ TUDCA before LPS challenge significantly reduced FITC-dextran leakage in the plasma (Figure 5a), and diminished enterocyte apoptosis (Figure 5b).

\section{TUDCA Inhibits Receptor-Mediated Apoptosis in Colonocytes In Vitro}

In IBD, intestinal epithelial apoptosis is modulated by several factors, including TNF and FasL. ${ }^{21,22}$ In the next set of experiments these triggers were used to assess the effects of TUDCA in vitro using the colonic HT29 and T84 cell lines. In colonocytes, bile acids are taken up by passive transport that may depend on the critical micellar concentration $(\sim 3 \mathrm{mM}$ for TUDCA ${ }^{23}$ ). First, to evaluate the cytotoxicity of TUDCA in the $1-10 \mathrm{mM}$ range, $\mathrm{LDH}$ release was measured in the 

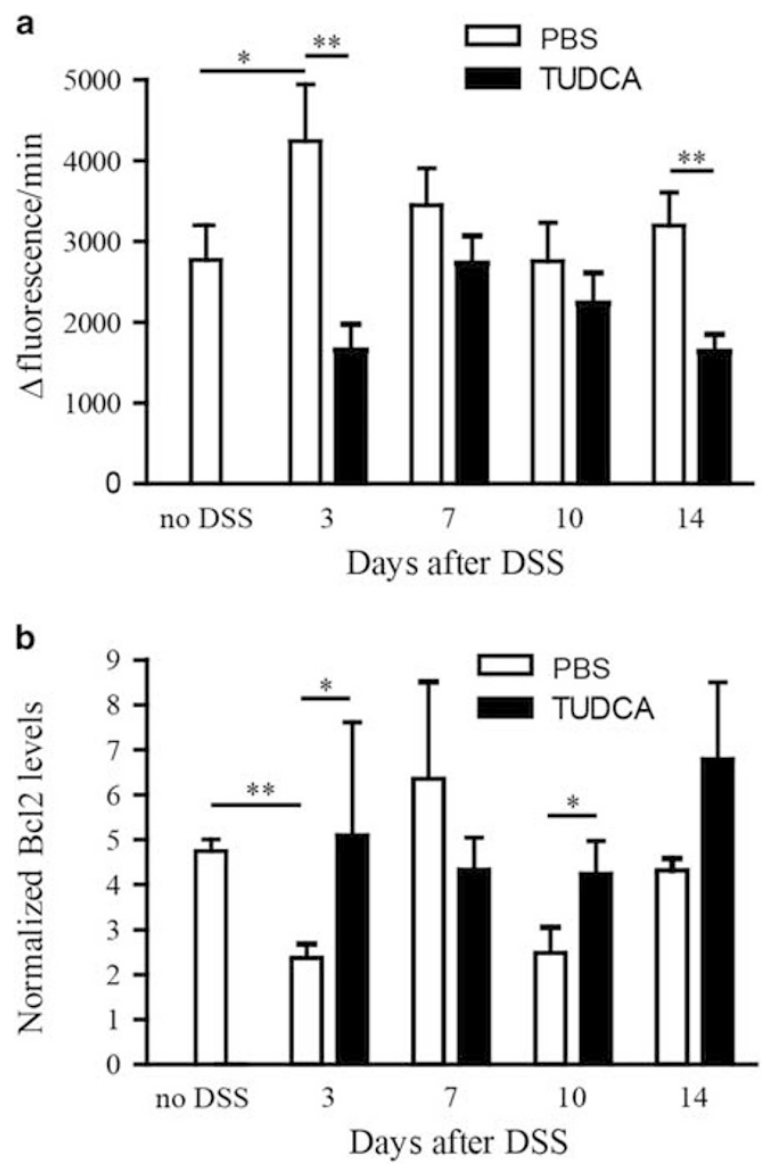

Figure 3 Apoptotic markers in freshly isolated colonic epithelial cells following DSS administration in TUDCA- and placebo-treated mice. (a) Caspase-3 activity assessed using a DEVD-fluorogenic assay and (b) $\mathrm{Bcl} 2$ mRNA levels measured by qRT-PCR. $N \geq 6$ at each time point. ${ }^{*} P<0.05$, ${ }^{* *} P<0.01$.

supernatant of HT29 epithelial cells incubated with increasing concentrations of TUDCA for $24 \mathrm{~h}$. No or even reduced LDH activity was observed in the supernatant of TUDCAtreated cells $(P=0.021$ at $10 \mathrm{mM}$ and $P=0.041$ at $5 \mathrm{mM}$; Table 3). Cell viability of TUDCA-treated cells, as determined by the MTT assay, was not affected, although a slight reduction was observed at $10 \mathrm{mM}(P=0.017$; Table 3$)$.

Apoptosis was induced by incubating cells with $100 \mathrm{ng} / \mathrm{ml}$ TNF and $300 \mathrm{ng} / \mathrm{ml}$ IFNG, which resulted in strong caspase$3,-8$, and -9 activation $(3.6-(P<0.001), 1.6-(P<0.05)$, and 1.6- $(P<0.01)$ fold, respectively; Figure 6 a; only caspase- 3 is shown) and increased cell death $(12.5 \%$ compared to $3.9 \%$; $P=0.002)$ after $24 \mathrm{~h}$. Cells that were simultaneously incubated with 1-10 mM TUDCA showed dose-dependent prevention of caspase- $3,-8$, and -9 activation (Figure 6a; only caspase- 3 is shown) and were significantly protected from cell death $(1.8 \%$ with $10 \mathrm{mM}$ TUDCA compared to $12.5 \%$ with TNF alone; $P=0.01$ ). Preincubating the cells for $6 \mathrm{~h}$ with TUDCA and subsequent washing of the cells, resulted in a significant but reduced protective effect as compared to co-incubation, suggesting that TUDCA elicits both direct and (intra)cellular molecular changes that protect the cells from TNF-induced apoptosis (Figure 6a). Electron microscopic analysis of T84 cells (forming a differentiated monolayer of cells) exposed to TNF demonstrated formation of apoptotic bodies, whereas the addition of $10 \mathrm{mM}$ TUDCA to the TNFtreated cells abolished all morphological signs of apoptosis (Figure 6b).

The addition of $200 \mathrm{ng} / \mathrm{ml}$ FasL to HT29 cells induces caspase-3 activation after $96 \mathrm{~h}(P<0.05$; Figure $7 \mathrm{a})$. Coincubation of FasL and TUDCA dose-dependently counteracts this induction (Figure 7a). Also, the preincubation of HT29 cells with TUDCA protected cells from caspase-3 activation.

\section{TUDCA Inhibits Receptor-Independent Apoptotic Signaling in Colonocytes}

Staurosporine is a well known proapoptotic agent that acts by inducing the intrinsic apoptosis pathway. The addition of $10 \mu \mathrm{M}$ staurosporine to HT29 cells resulted in increased caspase- 3 activation after $6 \mathrm{~h}(P<0.001$; Figure $7 \mathrm{~b})$. Again, the addition of TUDCA dose-dependently prevented caspase3 activation. However, preincubation with TUDCA sensitized the cells to staurosporine-induced caspase-3 activation (Figure $7 b$ ).

\section{The Anti-Apoptotic Effect of TUDCA is not Mediated by the $\alpha 5 \beta 1 /$ PI3K Pathway}

The $\alpha 5 \beta 1$ integrin receptor has been identified as a sensor for TUDCA in hepatocytes. ${ }^{24}$ In addition, the $\alpha 5$ subunit of this receptor has been linked with protection against apoptosis by a phosphatidylinositol 3-kinase (PI3K)/AKT-dependent mechanism. ${ }^{25}$ However, the addition of a specific inhibitor of PI3K signaling (wortmannin) or a blocking peptide of $\alpha 5 \beta 1$ integrin did not interfere with TUDCA-mediated protection of colonocytes against TNF-induced caspase-3 activation (Figures 8a and b).

\section{DISCUSSION}

In the present study, we identified the activation of caspase-3 in colonocytes as a very early event following DSS administration, occurring before the onset of clinical signs of gut inflammation. At the same time, the expression of $\mathrm{Bcl} 2$, an integral mitochondrial membrane protein that inhibits apoptosis, is significantly downregulated. In addition, caspase-3 expression and activity is increased in human UC samples, suggesting a central role for this apoptotic mediator in disease pathogenesis. We further demonstrated that the administration of TUDCA is able to prevent this proapoptotic signature and is associated with a considerable beneficial impact on the course of DSS-induced colitis. TUDCA preserved the gut barrier and protected mice from bacterial translocation to the circulation and death. In accordance with these findings, Casp 3 knockout mice are protected from 
a

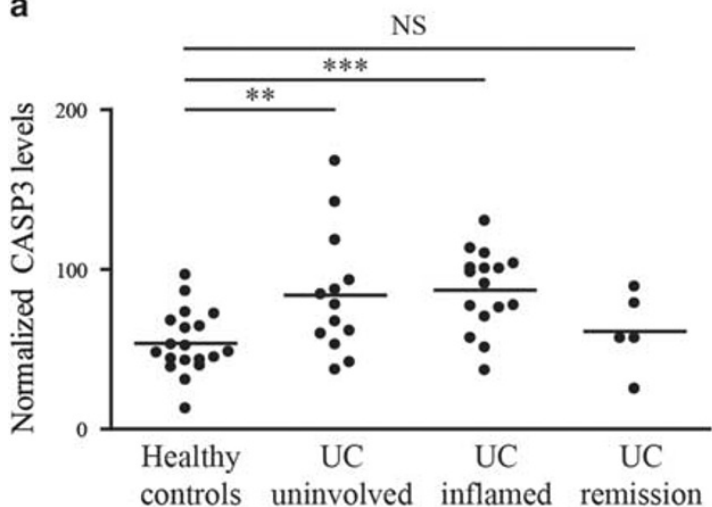

b

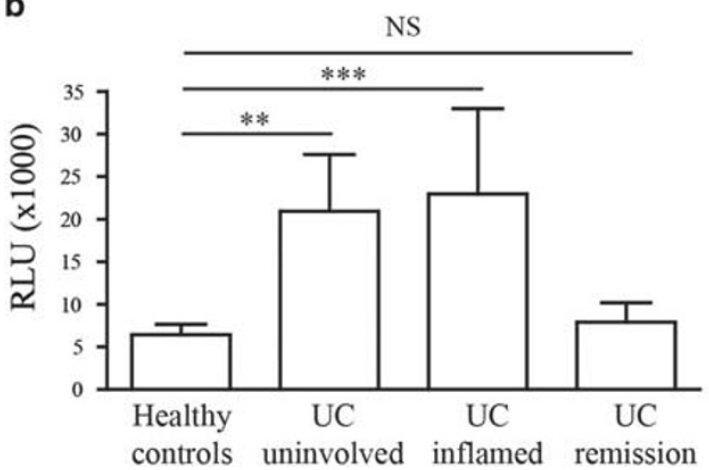

C

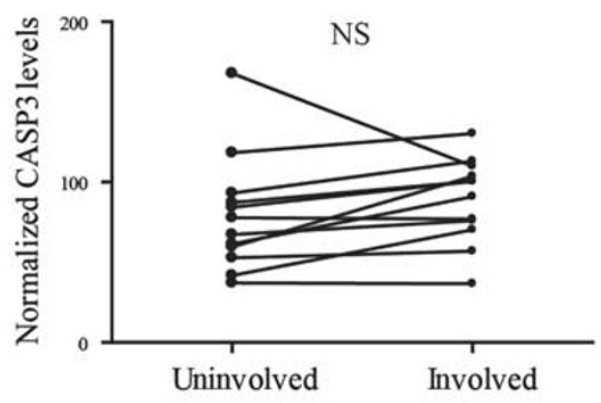

d

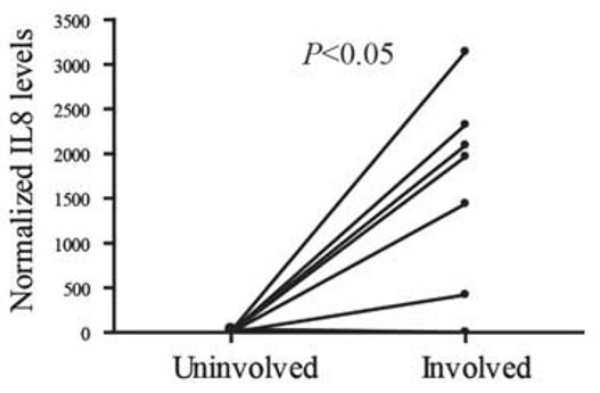

e
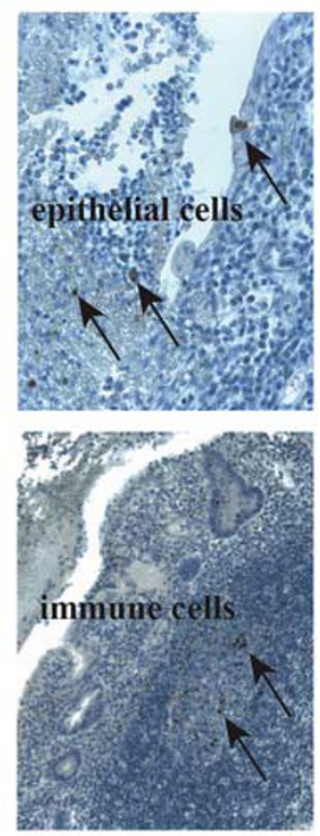

Figure 4 Caspase-3 expression in colonic biopsies of healthy controls and UC patients. (a) Caspase-3 mRNA levels and (b) activity in colonic biopsies retrieved from healthy controls, uninvolved areas of the colon of UC patients, in inflamed areas, and from UC patients in remission. (e) Staining for the cleaved form of caspase-3 in the colon of human UC showing positive colonocytes and inflammatory cells (arrows, e). (c and d) Subgroup analysis of samples in panel a demonstrating caspase-3 and IL8 expression in paired colonic biopsies retrieved from involved and uninvolved areas of the same UC patients revealed. ${ }^{*} P<0.01,{ }^{* *} P<0.001$. NS, not significant.
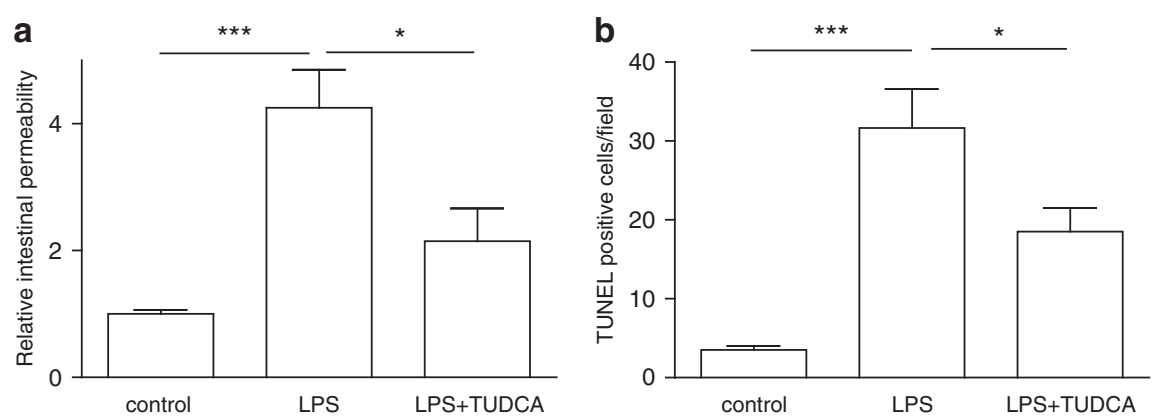

Figure 5 The effect of TUDCA on LPS-induced intestinal permeability and enterocyte apoptosis. Mice $(N=8)$ received $500 \mathrm{mg} / \mathrm{kg}$ TUDCA (i.p.) or PBS $24 \mathrm{~h}$ and $15 \mathrm{~min}$ before injection with $7 \mathrm{mg} / \mathrm{kg}$ LPS. (a) Orally fed FITC-dextran was detected in plasma and (b) TUNEL-positive ileal enterocytes were quantified in six fields per mouse $\times 400) .{ }^{*} P<0.05,{ }^{* * *} P<0.001$.

DSS-induced colitis $^{26}$ and $B c l 2$ knockout mice develop spontaneous colitis associated with increased apoptosis of epithelial cells located in the colonic crypts. ${ }^{27}$ In a second model, using LPS to induce enterocyte apoptosis and barrier disruption, the anti-apoptotic properties of TUDCA were evaluated. Again, prophylactic administration of TUDCA was able to reduce apoptosis and leakage of FITC-labeled dextran into systemic circulation.

Intestinal barrier defects have been demonstrated to precede relapses in human UC, ${ }^{1,28}$ with exaggerated colonic epithelial cell apoptosis being a major contributing factor. We support this finding by demonstrating increased caspase-3 
transcription and activity in both involved and uninvolved regions of the colon of UC patients. To demonstrate further that the biopsies that were collected from endoscopically inflamed areas also reflected true microscopic inflammation, we showed highly elevated IL8 levels in involved compared to non-involved areas from the same patients. It is particularly interesting that in UC patients, increased caspase-3 activity occurs in endoscopically intact mucosa, suggesting an

\section{Table 3 Cytotoxicity parameters in TUDCA-treated HT29 cells}

\begin{tabular}{lcc}
\hline & $\begin{array}{c}\text { LDH (nmol/min/ml) } \\
\text { mean } \pm \text { s.e.m., } N=3\end{array}$ & $\begin{array}{c}\text { MTT (OD570) } \\
\text { mean } \pm \text { s.e.m., } N=3\end{array}$ \\
\hline PBS & $2.02 \pm 0.06$ & $2.85 \pm 0.08$ \\
TUDCA, $10 \mathrm{mM}$ & $1.59 \pm 0.08^{¥}$ & $1.87 \pm 0.08^{¥}$ \\
TUDCA, $5 \mathrm{mM}$ & $1.68 \pm 0.02^{¥}$ & $2.55 \pm 0.10$ \\
TUDCA, $2.5 \mathrm{mM}$ & $2.00 \pm 0.05$ & $3.53 \pm 0.09$ \\
TUDCA, 1.25 mM & $2.00 \pm 0.06$ & $3.58 \pm 0.09^{¥}$ \\
Triton X-100, 1\% (cytotoxic & $20.00 \pm 0.40^{¥ ¥}$ & $0.06 \pm 0.01^{¥ ¥}$ \\
control) & & \\
\end{tabular}

LDH, lactate dehydrogenase; MTT, 3-(4,5-dimethylthiazol-2-yl)-2,5-diphenyltetrazolium bromide. ${ }^{\sharp} P<0.05,{ }^{¥ ¥} P<0.001$ compared to PBS. intrinsic defect that may render the mucosa susceptible to inflammation. Because inflammation in UC typically starts at the rectum and moves upwards, perhaps the bacterial load is an important trigger for overt inflammation.

Most of the bile acids released into the intestine are reabsorbed in the terminal ileum; however, with each cycle of the enterohepatic circulation, a proportion (up to $30 \%$ ) of the bile acid pool enters the large intestine. Here, bile acids undergo extensive modification by luminal bacteria, including deconjugation, dehydroxylation, and desulphonation, significantly altering the physicochemical properties of the bile acid pool. The role of bile acids as regulators of intestinal epithelial viability is currently under strong investigation. In particular, fecal dysbiosis in IBD was linked with dysmetabolism of bile salts, characterized by decreased levels of secondary bile acids. ${ }^{10}$ Although these secondary bile acids show anti-inflammatory effects on epithelial cells in vitro, ${ }^{10}$ they vary in hydrophobicity and cytotoxicity. Although hydrophobic bile acids have the potential to damage cell membranes, hydrophilic bile acids possess cytoprotective properties. ${ }^{9}$ A remarkable secondary bile salt that has long been studied for its cytoprotective actions is TUDCA, which is only found in trace amounts in human bile. The use of TUDCA has been proposed as a new therapeutic option for UC because of its ability to inhibit endoplasmic reticulum stress induced by

a

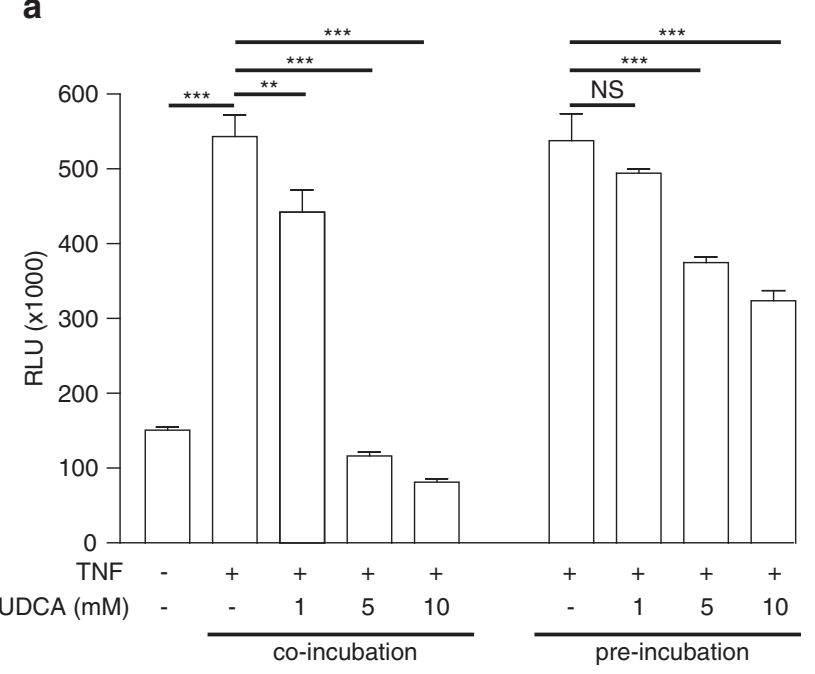

b
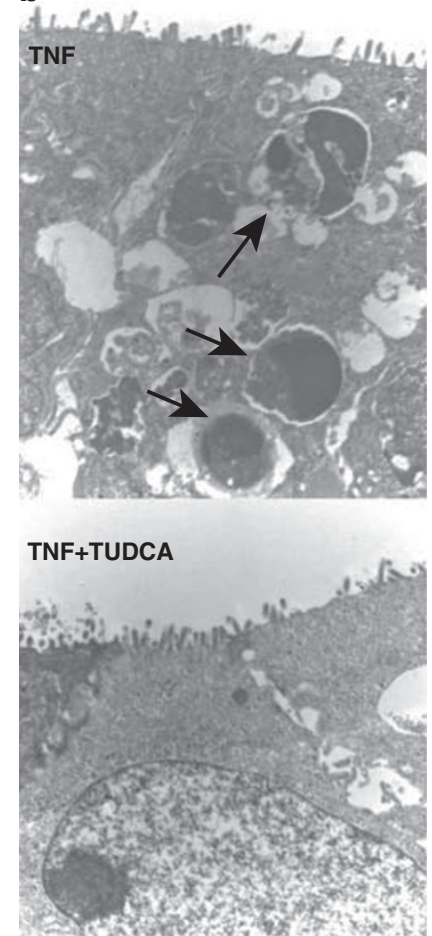

Figure 6 The effect of TUDCA on TNF-induced caspase-3 activation and apoptosis. (a) HT29 cells were stimulated with a combination of TNF and IFNG (TNF) for $24 \mathrm{~h}$ and treated with 1, 5, or $10 \mathrm{mM}$ TUDCA, or an equal volume of medium. In the preincubation setting, TUDCA was added for $6 \mathrm{~h}$, TUDCA was washed off and then the cells were stimulated with TNF for another $24 \mathrm{~h}$. $N=6$ for each condition and the experiment was repeated four times. (b) Electron microscopic images $(\times 7000)$ of a monolayer of T84 cells stimulated with TNF with and without 10 mM TUDCA. Apoptotic bodies are indicated with arrows. ${ }^{* *} P<0.01$ and ${ }^{* * *} P<0.001$. RLU, relative light units. 
a
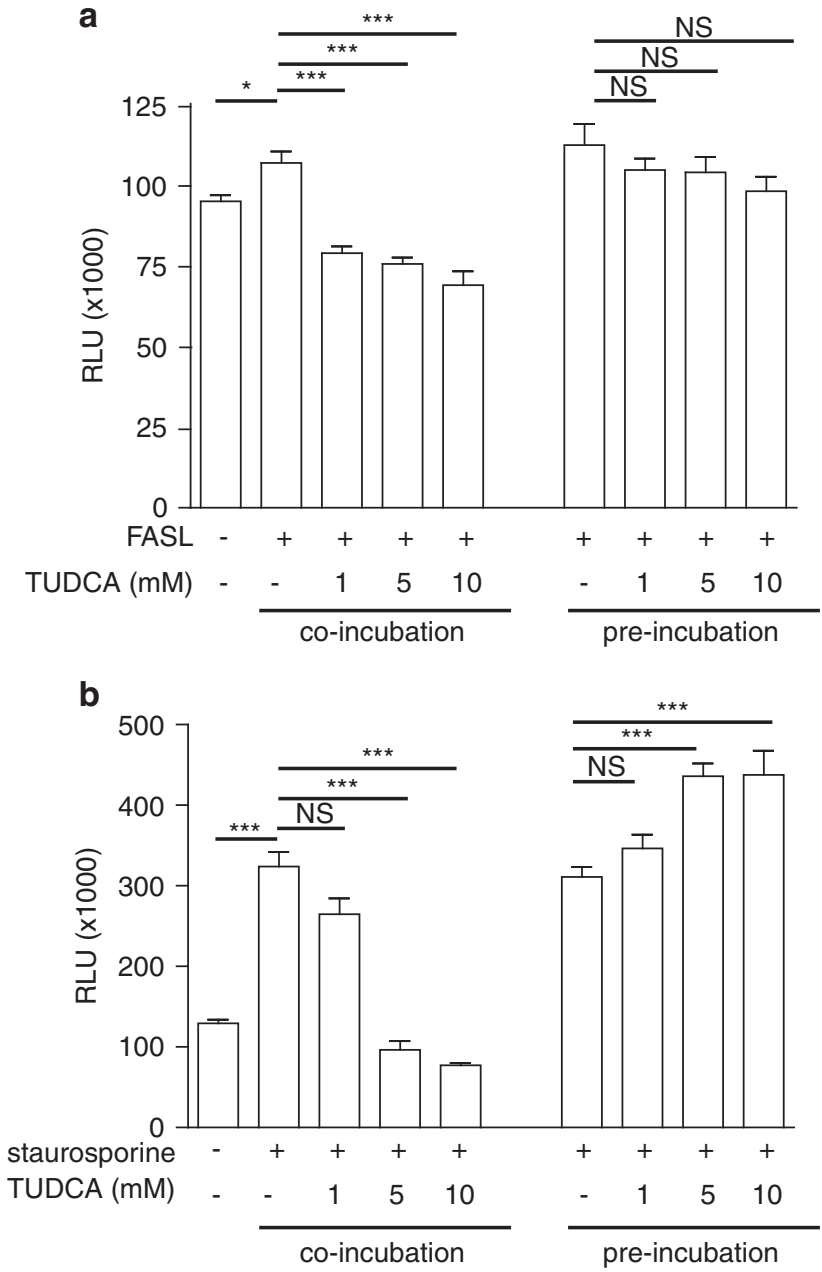

Figure 7 The effect of TUDCA on FasL- and staurosporine-induced caspase-3 activation. HT29 cells were incubated with $10 \mathrm{mM}$ TUDCA for $6 \mathrm{~h}$, TUDCA was washed off and then the cells were stimulated with (a) $200 \mathrm{ng} / \mathrm{ml}$ FasL for $72 \mathrm{~h}$ or (b) $10 \mu \mathrm{M}$ staurosporine for $6 \mathrm{~h}$ in combination with 1,5 , or $10 \mathrm{mM}$ TUDCA or an equal volume of medium. $N=3$ for each condition ${ }^{*} P<0.05$ and ${ }^{* *} P<0.001$. The experiment was repeated two times. NS, not significant; RLU, relative light units.
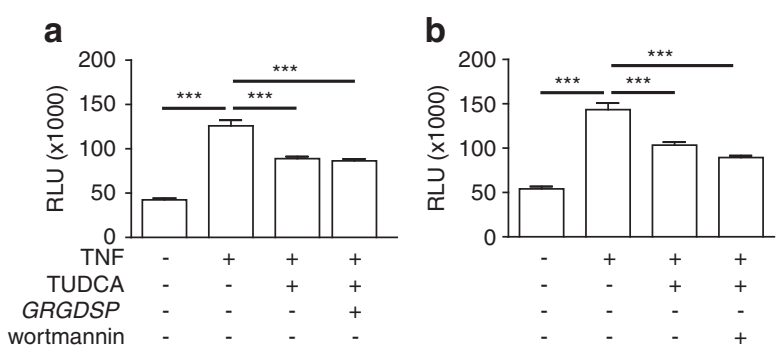

Figure 8 The effect of an $\alpha 5 \beta 1$ integrin-blocking peptide and a PI3K inhibitor on the protective effect of TUDCA toward TNF-induced caspase3 activation. HT29 cells were incubated with $10 \mathrm{mM}$ TUDCA for $6 \mathrm{~h}$; TUDCA was washed off and then the cells were stimulated with TNF for another $24 \mathrm{~h}$ with or without (a) $10 \mu \mathrm{M}$ GRGDSP-blocking peptide or (b) $100 \mathrm{nM}$ wortmannin. $N=6$ for each condition. ${ }^{* *} P<0.001$. RLU, relative light units. inflammatory stimuli. ${ }^{15,29}$ We provide evidence for a very early additional anti-apoptotic effect on intestinal epithelial cells preventing barrier damage. The most compelling protective effect of TUDCA was the absence of mortality caused by DSS administration. In general, once colitis is established after DSS administration, death follows in $20-60 \%$ of mice, depending on the concentration of the DSS and the environment of the animal facility. In our experiment, all mice that received DSS and TUDCA simultaneously survived, as compared to $60 \%$ of the mice that received DSS only. Weight loss induced by established colitis was also significantly less pronounced in TUDCA-treated mice. Moreover, the prevention of proapoptotic caspase- 3 activation in TUDCAtreated mice was associated with a reduced infiltration with neutrophils and a reduced expression of proinflammatory cytokines such as TNF, IL1B, and CXCL2.

The positive effect of TUDCA in acute DSS-induced colitis, known as a T-cell independent model, suggests that the beneficial effect of TUDCA on epithelial barrier function is independent of T-cell activation. Barrier disruption is associated with translocation of bacteria to the portal circulation. ${ }^{30}$ Consistent with its cytoprotective effect, reduced numbers of bacteria were found in the spleens of TUDCAtreated mice. On histology, TUDCA decreased the number of erosions and goblet cell depletion. Periodic acid-Schiff staining increased in these mice, suggesting elevated mucin production, which may help to limit the exposure time of luminal antigens with epithelial cells due to increased lubrification. DSS profoundly acts on various parameters that determine the thickness and function of the mucus layer, by directly destroying the mucus gel, interfering in mucin expression, their secretion and of course through goblet cell depletion. We did not observe a difference in mucus secretion in the early phases of DSS, however, during the restoration phase, PAS staining significantly increased. This observation has been reported elsewhere, where the authors show that this is partially mediated by iNOS. ${ }^{31}$

To strengthen the in vivo findings, epithelial cells were subjected to receptor-dependent and receptor-independent proapoptotic stimuli in vitro. A potent receptor-mediated trigger for apoptosis is TNF, a multifunctional cytokine that is excessively produced in IBD tissues and sustains chronic inflammation partly by inducing epithelial cell death. Also in the LPS-induced model of epithelial barrier disruption, TNF bioactivity plays a central role. ${ }^{20}$ Not surprisingly, monoclonal antibodies directed against TNF are widely and successfully used to treat IBD. This anti-TNF therapy promotes mucosal healing, and is associated with reduced epithelial apoptosis. ${ }^{32}$ We showed that TUDCA is able to dose-dependently inhibit TNF-induced caspase-3 activation in colonocytes during co-incubation. Moreover, preincubation of HT29 cells with TUDCA still resulted in reduced caspase-3 activation following TNF stimulation, albeit to a much lesser extent. Therefore, TUDCA protects cells from TNF in two independent ways: by directly sequestering TNF 
and by an additional direct mechanism on the cells. The involvement of $\alpha 5 \beta 1$ integrin and PI3K/AKT signaling was ruled out because TUDCA-mediated protection from TNF-induced caspase-3 activation is insensitive toward blocking PI3K by wortmannin or the $\alpha 5 \beta 1$ integrinblocking hexapeptide GRGDSP. In addition, TUDCA acts on the permeability of the mitochondrial membrane and the concomitant release of cytochrome $c{ }^{33}$ In HT29 cells, similar protection from TNF-induced cytochrome $c$ release from the mitochondria (data not shown), as well as caspase-9 activation, was observed. Finally, TUDCA could also interfere in cell membrane composition or structure and inhibit crosslinking of transmembrane TNF receptors. Next to TNF, TUDCA also confers protection toward another receptormediated apoptotic stimulus elicited by FasL. Moreover, TUDCA prevented the intrinsic non-receptor-mediated apoptosis pathway forced by staurosporine in a direct way. However, preincubation with TUDCA sensitized the cells to caspase-3 activation, suggesting a negative effect on the mitochondrial control of apoptosis in the presence of staurosporine. Taken together, TUDCA protects cells from apoptosis by directly sequestering the triggers and can additionally protect the cells from receptor-mediated apoptosis.

In the in vitro experiments, a marked effect of TUDCA on apoptosis was observed starting from $5 \mathrm{mM}$. As opposed to the active uptake of bile acids in small intestinal enterocytes, unconjugated bile acids are passively taken up by colonocytes, in a way that differs from conjugated bile acids. Because of their negative charge in the gastrointestinal lumen, conjugated bile acids are almost impermeable to cell membranes. Once the concentration exceeds the critical micellar concentration, passive diffusion occurs much faster, implicating 'passive micellar diffusion' as a major mechanism for the absorption of conjugated bile acids. ${ }^{34}$ For TUDCA, the critical micellar concentration is $\sim 3 \mathrm{mM},{ }^{23}$ consistent with the dose that elicits anti-apoptotic activity in HT29 cells. In this range, TUDCA is not toxic to colonocytes, as shown by the lack of LDH release or alterations in cell viability.

In conclusion, together with data that were recently published on the beneficial effects of TUDCA in colitis, the antiapoptotic mechanisms evaluated in this study provide additional evidence for a clinically relevant effect. Therefore, TUDCA merits clinical investigation for its use mainly in the prevention of barrier deficits associated with UC as an addon therapy to the immunosuppression.

\section{ACKNOWLEDGMENTS}

Dr Falk Pharmaceuticals kindly provided TUDCA for research purposes. Technical support was offered by Kim Olievier and Hilde Devlies and the authors would like to thank Ran Rumes for electron microscopy. This work was supported by Flemish grants (Research Foundation Flanders (FWO) project G.12 and krediet aan navorsers G.15253.12), a grant from the Crohn en Coiltis Vereniging and a concerted action grant from Ghent University (BOF12/GOA/008). DL and LVdB are paid by FWO grants (G.12982.13 and G.11J99.13N) and Y-PV and LD are sponsored by grants from the Special
Research Fund from Ghent University (01D20012 and 01D20510). PV is a senior full professor at Ghent University, holder of a Methusalem grant (BOF09/01M00709) from the Flemish Government. BMB is a senior postdoc paid by the Methusalem grant. Research in the Vandenabeele lab is supported by Belgian grants (Interuniversity Attraction Poles, IAP 7/32), Flemish grants (FWO G.0875.11, FWO G.0973.11, FWO G.0A45.12N, FWO G.0787.13N, and Methusalem grant-BOF09/01M00709), Ghent University grants (MRP, GROUP-ID consortium), a grant from the Foundation against Cancer (F94), and grants from the VIB.

\section{DISCLOSURE/CONFLICT OF INTEREST}

The authors declare no conflict of interest.

1. Hindryckx P, Laukens D. Intestinal barrier dysfunction: the primary driver of IBD? In: Karouin S (ed) Inflammatory Bowel DiseaseAdvances in Pathogenesis and Management, 2012.

2. Abreu MT, Palladino AA, Arnold ET, et al. Modulation of barrier function during Fas-mediated apoptosis in human intestinal epithelial cells. Gastroenterology 2000;119:1524-1536.

3. Watson AJ, Chu S, Sieck L, et al. Epithelial barrier function in vivo is sustained despite gaps in epithelial layers. Gastroenterology 2005; 129:902-912.

4. Edelblum KL, Yan F, Yamaoka T, et al. Regulation of apoptosis during homeostasis and disease in the intestinal epithelium. Inflamm Bowel Dis 2006;12:413-424.

5. Dirisina R, Katzman RB, Goretsky T, et al. p53 and PUMA independently regulate apoptosis of intestinal epithelial cells in patients and mice with colitis. Gastroenterology 2011;141:1036-1045.

6. Koshiji M, Adachi $\mathrm{Y}$, Sogo $\mathrm{S}$, et al. Apoptosis of colorectal adenocarcinoma (COLO 201) by tumour necrosis factor-alpha (TNFalpha) and/or interferon-gamma (IFN-gamma), resulting from downmodulation of Bcl-2 expression. Clin Exp Immunol 1998;111:211-218.

7. Namba T, Tanaka K, Ito $Y$, et al. Positive role of CCAAT/enhancerbinding protein homologous protein, a transcription factor involved in the endoplasmic reticulum stress response in the development of colitis. Am J Pathol 2009;174:1786-1798.

8. Araki $\mathrm{Y}$, Mukaisyo $\mathrm{K}$, Sugihara $\mathrm{H}$, et al. Increased apoptosis and decreased proliferation of colonic epithelium in dextran sulfate sodium-induced colitis in mice. Oncol Rep 2010;24:869-874.

9. Stenman LK, Holma R, Forsgård R, et al. Higher fecal bile acid hydrophobicity is associated with exacerbation of dextran sodium sulfate colitis in mice. J Nutr 2013;143:1691-1697.

10. Duboc H, Rajca $S$, Rainteau $D$, et al. Connecting dysbiosis, bile-acid dysmetabolism and gut inflammation in inflammatory bowel diseases. Gut 2012;62:531-539.

11. Araki $Y$, Katoh T, Ogawa A, et al. Bile acid modulates transepithelial permeability via the generation of reactive oxygen species in the Caco-2 cell line. Free Radic Biol Med 2005;39:769-780.

12. Raimondi F, Santoro P, Barone MV, et al. Bile acids modulate tight junction structure and barrier function of Caco-2 monolayers via EGFR activation. Am J Physiol Gastrointest Liver Physiol 2008;294:G906G913.

13. Zhou Y, Doyen R, Lichtenberger LM. The role of membrane cholesterol in determining bile acid cytotoxicity and cytoprotection of ursodeoxycholic acid. Biochim Biophys Acta 2009;1788: 507-513.

14. Amaral JD, Viana RJ, Ramalho RM, et al. Bile acids: regulation of apoptosis by ursodeoxycholic acid. J Lipid Res 2009;50:1721-1734.

15. Cao SS, Zimmermann EM, Chuang BM, et al. The unfolded protein response and chemical chaperones reduce protein misfolding and colitis in mice. Gastroenterology 2013;144:989-1000.

16. Mantopoulos D, Murakami Y, Comander J, et al. Tauroursodeoxycholic acid (TUDCA) protects photoreceptors from dell death after experimental retinal detachment. PLoS One 2011;6:e24245.

17. Perreault N, Beaulieu JF. Primary cultures of fully differentiated and pure human intestinal epithelial cells. Exp Cell Res 1998;24: 34-42.

18. Bradley PP, Priebat DA, Christensen RD, et al. Measurement of cutaneous inflammation: estimation of neutrophil content with an enzyme marker. J Invest Dermatol 1982;78:206-209. 
19. Van der Sluis M, De Koning BA, De Bruijn AC, et al. Muc2-deficient mice spontaneously develop colitis, indicating that MUC2 is critical for colonic protection. Gastroenterology 2006;131:117-129.

20. Vandenbroucke RE, Dejonckheere E, Van Hauwermeiren F, et al. Matrix metalloproteinase 13 modulates intestinal epithelial barrier integrity in inflammatory diseases by activating TNF. EMBO Mol Med 2013;5:932-948.

21. Onizawa M, Nagaishi T, Kanai T, et al. Signaling pathway via TNFalpha/NF-kappaB in intestinal epithelial cells may be directly involved in colitis-associated carcinogenesis. Am J Physiol Gastrointest Liver Physiol 2009;296:G850-G859.

22. Vetuschi A, Latella $G$, Sferra $R$, et al. Increased proliferation and apoptosis of colonic epithelial cells in dextran sulfate sodium-induced colitis in rats. Dig Dis Sci 2002;47:1447-1457.

23. Olgun A, Köksal Z, Çoban A. The effect of reducing endoplasmic reticulum stress by tauroursodeoxycholic acid on Caenorhabditis elegans lifespan. Hacettepe J Biol Chem 2010;38:287-290.

24. Gohlke H, Schmitz B, Sommerfeld A, et al. $\alpha 5 \beta 1$-integrins are sensors for tauroursodeoxycholic acid in hepatocytes. Hepatology 2013;57:1117-1129.

25. Lee $\mathrm{L}$, Juliano RL. $\alpha 5 \beta 1$ integrin protects intestinal epithelial cells from apoptosis through a phosphatidylinositol 3-kinase and protein kinase B-dependent pathway. Mol Biol Cell 2000;11: 1973-1987.
26. Brinkman BM, Becker A, Ayiseh RB, et al. Gut microbiota affects sensitivity to acute DSS-induced colitis independently of host genotype. Inflamm Bowel Dis 2013;19:2560-2567.

27. Pritchard DM, Potten CS, Korsmeyer SJ, et al. Damage-induced apoptosis in intestinal epithelia from bcl-2-null and bax-null mice: investigations of the mechanistic determinants of epithelial apoptosis in vivo. Oncogene 1999;18:7287-7293.

28. Kiesslich R, Duckworth CA, Moussata D, et al. Local barrier dysfunction identified by confocal laser endomicroscopy predicts relapse in inflammatory bowel disease. Gut 2012;61:1146-1153.

29. Berger E, Haller D. Structure-function analysis of the tertiary bile acid TUDCA for the resolution of endoplasmic reticulum stress in intestinal epithelial cells. Biochem Biophys Res Commun 2011;409:610-615.

30. Berg RD. Bacterial translocation from the gastrointestinal tract. Adv Exp Med Biol 1999;473:11-30.

31. Schreiber O, Petersson J, Waldén T, et al. iNOS-dependent increase in colonic mucus thickness in DSS-colitic rats. PLoS One 2013;8:e71843.

32. Goretsky $T$, Dirisina $R$, Sinh $\mathrm{P}$, et al. p53 mediates TNF-induced epithelial cell apoptosis in IBD. Am J Pathol 2012;151:1306-1315.

33. Rodrigues CM, Solá S, Sharpe JC, et al. Tauroursodeoxycholic acid prevents Bax-induced membrane perturbation and cytochrome C release in isolated mitochondria. Biochemistry 2003;18:3070-3080.

34. Alrefai WA, Gill RK. Bile acid transporters: structure, function, regulation and pathophysiological implications. Pharm Res 2007;24:1803-1823. 